\title{
Preparation burning may not improve short-term seed survival in an Amazonian savanna
}

\author{
Victor J. U. R Rodriguez Chuma $^{1}$, Darren Norris ${ }^{1,2,3, *}$ (D), Taires P. da Silva ${ }^{1}$, Jéssica A. da Silva ${ }^{1}$, \\ Keison S. Cavalcante ${ }^{1}$, Igor A. P. Sidônio ${ }^{1}$, Adriano F. de Souza ${ }^{1}$, Daniel S. S. Valentim ${ }^{1}$, \\ Silas Mochiutti ${ }^{4}$ and Fernanda Michalski ${ }^{1,2,5}$

\begin{abstract}
${ }^{1}$ Programa de Pós-Graduação em Biodiversidade Tropical, Universidade Federal do Amapá, Rod. Juscelino Kubitscheck, km 02, 68903-419, Macapá, AP, Brazil, ${ }^{2}$ Ecology and Conservation of Amazonian Vertebrates Research Group, Universidade Federal do Amapá, Rod. Juscelino Kubitscheck, km 02, 68903-419, Macapá, AP, Brazil, ${ }^{3}$ Departamento de Meio Ambiente e Desenvolvimento, Coordenação de Ciências Ambientais, Universidade Federal do Amapá, Rod. Juscelino Kubitschek Km 02, 68902-419 Macapá, AP, Brazil, ${ }^{4}$ Empresa Brasileira de Pesquisa Agropecuária, Rod. Juscelino Kubitscheck, km 05, 68903-419, Macapá, AP, Brazil, and ${ }^{5}$ Instituto Pró-Carnívoros, Av. Horácio Neto 1030, 12945-010, Atibaia, SP, Brazil

*Corresponding author. E-mail: dnorris75@gmail.com
\end{abstract}

(Received 11 January 2021; Revised 03 February 2021; Accepted 03 February 2021)

\begin{abstract}
The role of fire in the management of degraded areas remains strongly debated. Here we experimentally compare removal and infestation of popcorn kernels (Zea mays L. - Poaceae) and açaí fruits (Euterpe oleracea Mart. - Arecaceae) in one burned and two unburned savanna habitats in the eastern Brazilian Amazon. In each habitat, a total of ten experimental units (five per seed type) were installed, each with three treatments: (1) open access, (2) vertebrate access, and (3) invertebrate access. Generalized linear models showed significant differences in both seed removal $(\mathrm{P}<0.0001)$ and infestation $(\mathrm{P}<0.0001)$ among seed type, habitats and access treatments. Burned savanna had the highest overall seed infestation rate $(24.3 \%)$ and invertebrate access increased açaí seed infestation levels to $100 \%$ in the burned savanna. Increased levels of invertebrate seed infestation in burned savanna suggest that preparation burning may be of limited use for the management and restoration of such habitats in tropical regions.
\end{abstract}

Keywords: invertebrates; seed fate; vertebrates

\section{Introduction}

Tropical savannas have been heavily impacted by anthropogenic land-cover conversion for agriculture. Agriculture now occupies nearly 1 million $\mathrm{km}^{2}$ of the Brazilian "Cerrado" savanna, or $\sim 50 \%$ of the biome's original extent (Lapola et al., 2014). However, after short periods of use many of the marginal agricultural areas are abandoned, particularly in smallholdings $(<100 \mathrm{ha})$, which represent approximately $25 \%$ of agricultural land-cover (Lapola et al., 2014).

Regenerative agroforestry has been shown to recover productive biodiverse ecosystems from abandoned degraded lands in tropical Brazil (Vieira et al., 2009; Yamada \& Gholz, 2002). Although attention has focused on Amazonian (Browder et al., 2005; Yamada \& Gholz, 2002) and Atlantic Forest (Ferreira et al., 2020; Santos et al., 2019) regions, smallholders in savanna regions are also likely to benefit from regenerative agroforestry (Lambers et al., 2020; Miccolis et al., 2017). Wildfires are the main determinants

\footnotetext{
(c) The Author(s), 2021. Published by Cambridge University Press. This is an Open Access article, distributed under the terms of the Creative Commons Attribution licence (http://creativecommons.org/licenses/by/4.0), which permits unrestricted re-use, distribution and reproduction, provided the original article is properly cited.
} 
of vegetation composition in savannas (Chidumayo, 2013), yet empirical evidence documenting how fire influences regenerative agroforestry in Brazilian savanna smallholdings remains scarce.

Fire (Moura et al., 2019) and seed predation (Ferreira et al., 2011) are expected to strongly influence regenerative potential of degraded Brazilian savannas. The use of fire remains controversial for the management and restoration of Brazilian savanna areas (Carmenta et al., 2019; Eloy et al., 2019). Trees may be killed by fire and if fire regimes do not allow seed banks to recover before repeated ignition events it may even cause local extinctions (Auld et al., 2007). Alternatively fire can serve as a trigger for germination, release nutrients into the soil and prepare soil surface to receive new seeds. Seed mortality is high in tropical regions due to predation, desiccation and rot (Cole, 2009). Thus, seed predation plays a key role in structuring plant populations and communities with post-dispersal seed predation causing extensive seed loss (Curran \& Webb, 2000; Ferreira et al., 2011; Hulme, 1998).

\section{Objectives}

Our objective was to compare seed infestation and removal in burned and unburned savanna areas. We hypothesize that burned savanna areas will have lower seed removal/infestation compared with unburned areas. To test this hypothesis we experimentally compared seed removal and seed infestation rates of seeds from two non-legume species [popcorn kernels (Zea mays L. - Poaceae) and açaí fruits (Euterpe oleracea Mart. - Arecaceae, Supplemental Material S1] in one burned and two unburned savanna areas.

\section{Methods}

The study was conducted at the Campo Experimental do Cerrado (CEC) of Embrapa-Amapá $\left(0^{\circ} 2^{\prime} 5^{\prime \prime} \mathrm{N}\right.$, $51^{\circ} 2^{\prime} 2^{\prime \prime} \mathrm{W}$, Figure 1). A month before the study wildfire passed across part of the CEC, providing an ideal
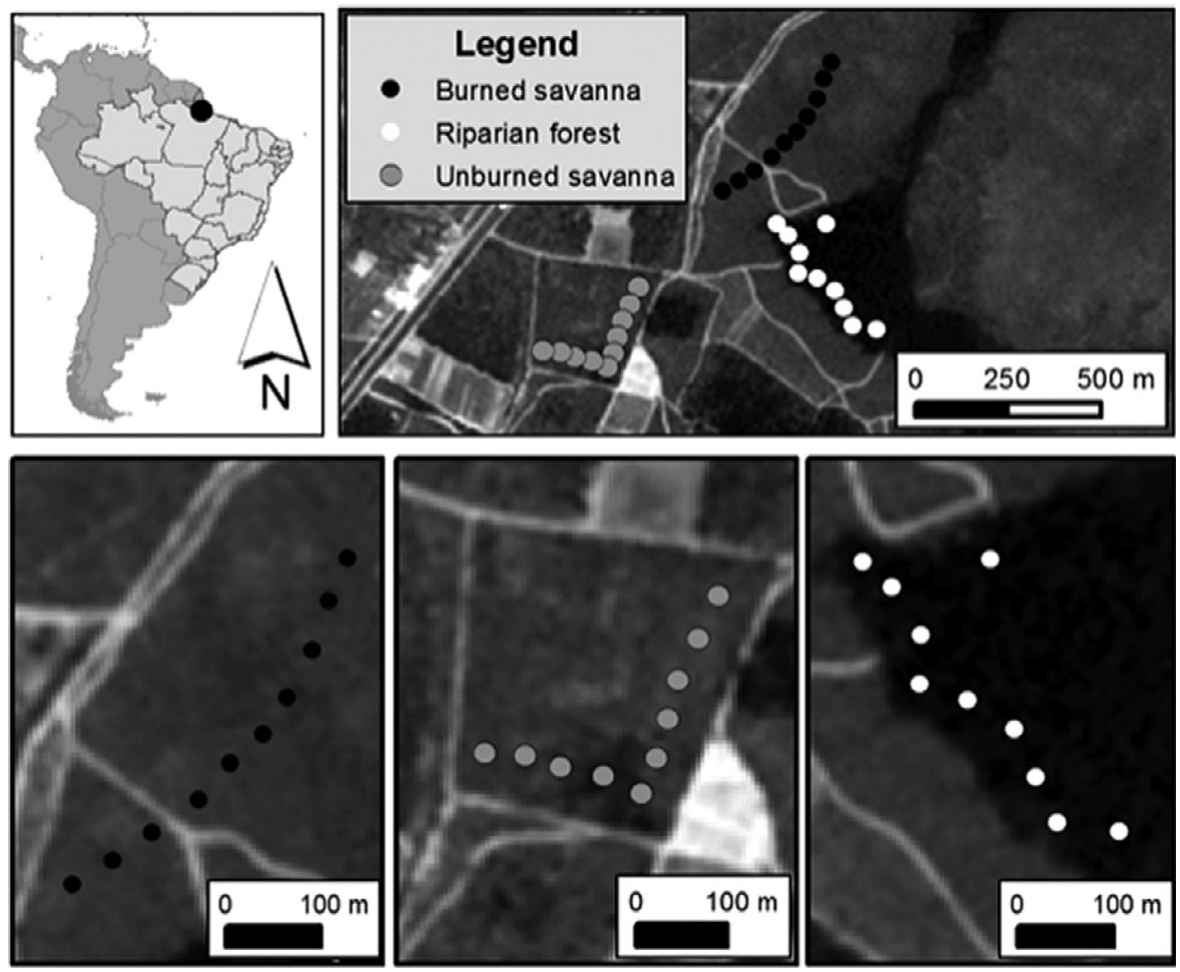

Figure 1. Location of the study region in the Campo Experimental do Cerrado (CEC) of Embrapa-Amapá, Amapá state, Brazil, showing the 30 seed removal units monitored (10 black, 10 white and 10 grey circles representing burned savanna, riparian savanna forest, and unburned savanna, respectively). 
natural experiment to test seed removal in burned and unburned savanna habitats. We set our experiment in three habitat types (Figure 1, Supplemental Material S2): burned savanna (BS) with the most recent wildfire recorded one month before the experiment, unburned savanna (US) with over 20 years without any record of wildfire, and unburned riparian savanna forest (RF) with no record of wildfire.

In each habitat type (BS, US, and RF) we established 10 experimental units (five per seed type), $50 \mathrm{~m}$ apart from each other (Kaspari, 1993). We alternated experimental units between palm fruits and popcorn kernels. In order to identify the seed removers we used three selective access treatments (Supplemental Material S3): (1) open access, with all seeds or fruits placed on the soil surface so that any bird, mammal or invertebrate could access; (2) vertebrate access, when ants and other invertebrates were excluded by a $2-3 \mathrm{~cm}$ circular moat around the seeds/fruits; and (3) invertebrate access, where vertebrates were excluded by covering the seeds/fruits with a protective wire tower $(5 \mathrm{~mm}$ mesh, 15-20 cm high) (Christianini \& Galetti, 2007; Ferreira et al., 2011; Norris \& Michalski, 2010; Tasker et al., 2011). In each experimental unit, the three treatments each contained 10 seeds or fruits separated by $1 \mathrm{~m}$. To avoid confounding edge effects experimental units were placed along transects that were established at a fixed distance of $50 \mathrm{~m}$ from any nearest habitat edge. We monitored experiments for four consecutive days, providing a total of 79 observation hours at each habitat type simultaneously, between 13 and 16 November 2015 (see Supplemental Material S2 and S3 for further details). Although previous studies in Brazilian savannas demonstrate that most seed/fruit removal occurred within $24 \mathrm{~h}$ (Alexander et al., 2007; Ferreira et al., 2011) we allowed seeds to remain exposed for four days to provide a more complete assessment of seed removal and infestation rates (Ferreira et al., 2011).

The fate of kernels/fruits was classified as removed, infested (when invertebrates entered internally e.g. entered beyond the exocarp) or intact. To identify if kernel/fruit removal and infestation varied among habitats, seed type and treatments we used Generalized Linear Models (GLMs, binomial error distribution). Variograms (Figure 2) were used to test for spatial autocorrelation in model residuals (Cressie, 1993; Legendre, 1993). All analyses were conducted in R (R Development Core Team, 2019), with functions available in geoR (Ribeiro Jr \& Diggle, 2001) and tidyverse (Wickham et al., 2019) packages.

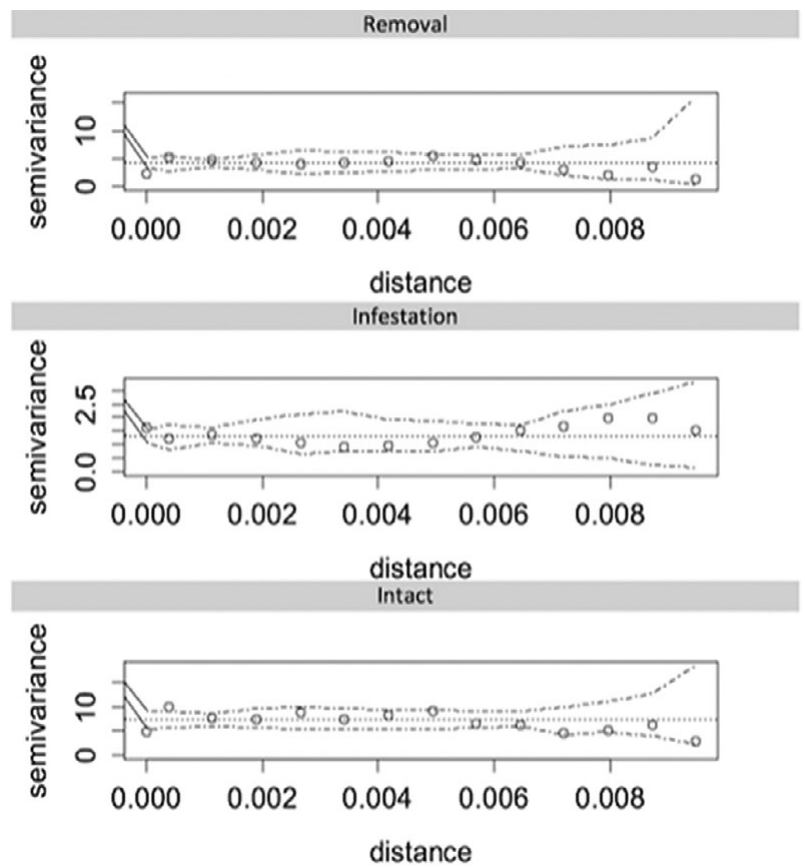

Figure 2. Sample semi-variograms and simulation envelopes under random permutation of GLM residuals. Distance calculated from geographic coordinates (decimal degrees, $0.001 \approx 100 \mathrm{~m}$ ). 


\section{Results}

The type of habitat, treatment and seed had significant effects on the probability of removal and infestation (Figure 3, Table 1). More popcorn kernels remained intact compared with açaí fruits (Figure 3, Table 1). Although popcorn experienced increased removal there was less infestation compared with açaí (Figure 3, Table 1). The number of fruits and kernels removed $(\mathrm{P}<0.0001)$ and infested $(\mathrm{P}<0.0001)$ varied significantly among habitat types (Figure 3, Table 1$)$. The greatest removal rates $(25.5 \%)$ were recorded in the riparian savanna forest, followed by the unburned and burned savannas, with 5.3\% and $1.3 \%$ removal, respectively (Figure 3). The variograms used to test for spatial autocorrelation in model residuals (Figure 2) did not show spatial correlation for any treatment. Indeed, variograms showed a lack of pattern and/or trend, demonstrating that the unexplained variation in our GLMs was also not explained by spatial autocorrelation.

Neither fruits nor kernels were removed from burned areas, however 100\% infestation occurred when invertebrates had access to açaí fruits in burned areas (Figure 3). The proportion of infested seeds/fruits
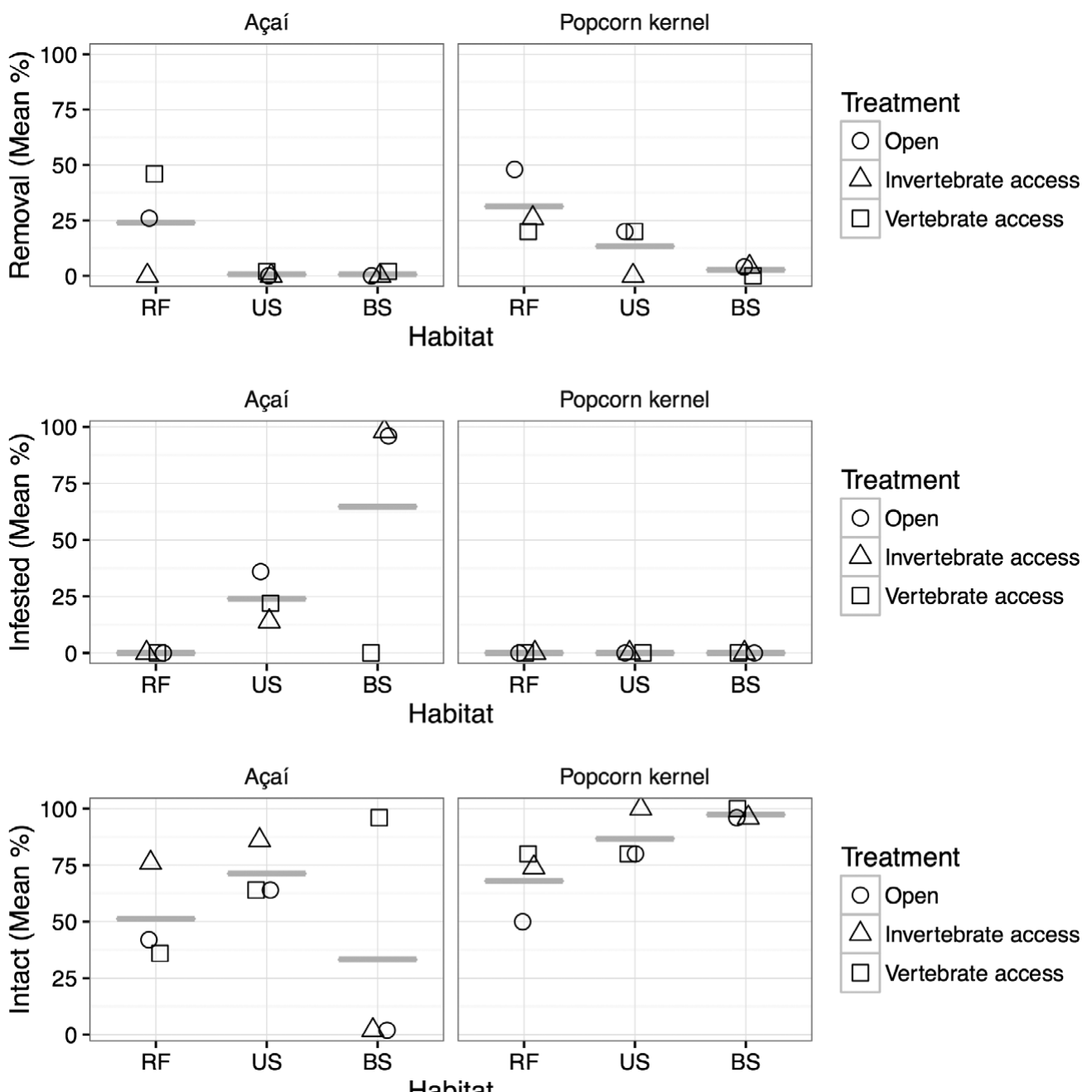

\section{Treatment}

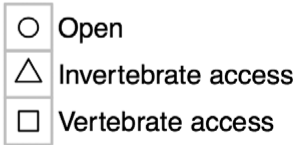

Figure 3. Short-term fate of açaí fruit and popcorn kernels in an Amazonian savanna. Comparison of percentage removed, infested and number of intact açaí fruits and popcorn kernels. Experiments were conducted in three habitats (RF - Riparian Savanna Forest, US - Unburned savanna, and BS - Burned savanna) in November 2015. In each habitat the fruits and kernels were placed in three treatments (Open, Invertebrate access, and Vertebrate access). 
Table 1. Generalized Linear model results. Three binomial responses were used to examine short-term seed fate in an Amazonian savanna: i) Removal, ii) Infestation and iii) Number of intact seeds.

\begin{tabular}{|c|c|c|c|c|c|c|c|c|c|}
\hline \multirow[b]{2}{*}{ Factor } & \multicolumn{3}{|c|}{ Removal } & \multicolumn{3}{|c|}{ Infestation } & \multicolumn{3}{|c|}{ Intact } \\
\hline & ${ }^{\mathrm{a}} \mathrm{DE}$ & Est. (SE) & Z & ${ }^{\mathrm{a}} \mathrm{DE}$ & Est. (SE) & Z & ${ }^{\mathrm{a}} \mathrm{DE}$ & Est. (SE) & Z \\
\hline Habitat & 20.0 & & & 25.8 & & & 3.4 & & \\
\hline Unburned & & $-1.7(0.3)$ & $-6.4^{\star \star \star}$ & & $20.5(226.2)$ & 0.0 & & $1.1(0.2)$ & $5.5^{\star \star \star}$ \\
\hline Burned & & $-3.2(0.5)$ & $-6.8^{\star \star \star}$ & & $23.0(226.2)$ & 0.0 & & $0.3(0.2)$ & 1.6 \\
\hline Treatment & 5.1 & & & 10.3 & & & 3.9 & & \\
\hline Invert & & $-1.4(0.3)$ & $-4.6^{\star \star \star}$ & & $-0.6(0.3)$ & $-1.7^{+}$ & & $0.9(0.2)$ & $4.6^{\star \star \star}$ \\
\hline Vert & & $-0.1(0.2)$ & -0.5 & & $-3.6(0.5)$ & $-7.7^{\star \star \star}$ & & $1.1(0.2)$ & $5.6^{\star \star \star}$ \\
\hline${ }^{\mathrm{b}}$ Seed & 2.6 & $0.8(0.2)$ & $3.6^{\star \star \star}$ & 44.9 & $-22.9(204.1)$ & -0.0 & 14.2 & $1.7(0.2)$ & $10.2^{\star \star \star}$ \\
\hline Model & 27.7 & & & 81.0 & & & 21.5 & & \\
\hline
\end{tabular}

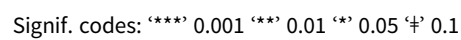

a Percentage of model deviance explained.

bopcorn compared to açaí.

Bold text indicates a statistically significant difference with a $p<0.05$.

was higher on average in the burned savanna (24.3\%), followed by unburned savanna (9.0\%), while the riparian savanna forest had no infested seeds/fruits.

\section{Discussions}

We found that vertebrate access increased removal of açaí fruits in the riparian savanna area. A preference for habitats with dense vegetation cover, in order to avoid predation while searching for food (Souza-Silva et al., 2015) could explain the higher vertebrate removal rates in the riparian savanna forest compared to more exposed burned and unburned savannas.

Our findings agree with previous studies that show how both insects and fire influence the structure and composition of savanna vegetation (Alexander et al., 2007; Costa et al., 2017; Maravalhas \& Vasconcelos, 2014; Oliveira \& Freitas, 2004). The increased açaí infestation rates in the burned and unburned savanna habitats were related with the occurrence of termites, which were not observed in unburned riparian savanna forest. After only four days we demonstrated that $100 \%$ of invertebrate infestation occurred when invertebrates had access to açaí fruits in burned areas, which clearly demonstrates the differences in invertebrate infestation between burned and unburned areas.

Although previous studies have largely focused on the role of ants (Alexander et al., 2007; Costa et al., 2017; Maravalhas \& Vasconcelos, 2014; Oliveira \& Freitas, 2004) our findings suggest that additional studies are needed to establish how termites influence recruitment and regeneration patterns in Brazilian savanna areas. Through diverse relationships with microorganisms termites may exploit living and/or dead plant tissues (Logan et al., 1990) and termite predation can affect seed viability (Nwosu \& Akor, 2018). The high infestation of seeds/fruits in burned savanna areas agrees with findings from South Africa (Davies et al., 2012) and Australia (Avitabile et al., 2015) that show how termites are resistant to savanna fires. Additionally the rapid infestation rates in both burned and unburned habitats is likely to generate challenges for conservationists and managers to restore degraded areas in tropical savanna regions.

Our results should be interpreted carefully as we conducted our experiment for a short period and without more replicates within the different habitats. Although previous studies show that most removal occurs within 24 hours (Alexander et al., 2007; Ferreira et al., 2011), it is possible that over time the removal and infestation levels may continue to increase in the different habitats. Considering that we did not establish if infestation affected seed viability, additional longer term (multi-year) experiments 
focusing on germination and recruitment with more species are needed to establish the viability of different agroforestry options in the region. As such our findings support previous studies (Lambers et al., 2020; Miccolis et al., 2017) that show how the development of effective restoration and/or agroforestry will depend on detailed experimental evidence to enable development of the most cost and time effective actions in Brazilian savannas.

\section{Conclusions}

In this study, the type of habitat, treatment and seed had significant effects on the probability of seed removal and infestation. Overall, more popcorn kernels remained intact compared with açaí fruits. Yet, burned savanna areas showed $100 \%$ invertebrate seed infestation rates. These findings suggest that preparation burning in isolation may not be effective for regenerative agroforestry and that the management and restoration potential in burned Amazon savannas could be severely limited by invertebrate infestation.

Acknowledgements. We are deeply indebted for the Brazilian Agricultural Research Corporation (EMBRAPA) for providing research permit and logistical support. The Federal University of Amapá also provided logistical support. This article resulted from the PPGBIO field ecology course in 2015. This study is dedicated to the memory of Dr. Silas Mochiutti, whose kindness and curiosity inspired us all.

Author Contributions. DN, FM and SM conceived and designed the study. VJUR, TPS, JAS, KSC, IAPS, AFS, DSSV, SM and FM conducted data gathering. DN performed statistical analyses. VJUR, TPS, JAS, KSC, IAPS, AFS, DSSV, SM, DN and FM wrote the original draft. All authors revised the text.

Financial Support: Statement. We thank the Postgraduate Program in Tropical Biodiversity (PPGBIO) of the Federal University of Amapá for providing funding.

Conflicts of Interest. All authors declare none.

Data Availability Statement. All materials needed to replicate the findings of the article are available as Supplementary Materials.

Supplementary Materials. To view supplementary material for this article, please visit http://dx.doi.org/10.1017/exp.2021.2.

\section{References}

Alexander, V. C., Antônio, J. M.-N., \& Oliveira, P. S. (2007). The role of ants in the removal of non-myrmecochorous diaspores and seed germination in a neotropical savanna. Journal of Tropical Ecology, 23, 343-351.

Auld, T. D., Denham, A. J., \& Turner, K. (2007). Dispersal and recruitment dynamics in the fleshy-fruited Persoonia lanceolata (Proteaceae). Journal of Vegetation Science, 18, 903-910. https://doi.org/10.1111/j.1654-1103.2007.tb02606.x.

Avitabile, S. C., Nimmo, D. G., Bennett, A. F., \& Clarke, M. F. (2015). Termites are resistant to the effects of fire at multiple spatial scales. PLOS ONE, 10, e0140114. https://doi.org/10.1371/journal.pone.0140114.

Browder, J. O., Wynne, R. H., \& Pedlowski, M. A. (2005). Agroforestry diffusion and secondary forest regeneration in the Brazilian Amazon: Further findings from the Rondônia Agroforestry Pilot Project (1992-2002). Agroforestry Systems, 65, 99-111. https://doi.org/10.1007/s10457-004-6375-9.

Carmenta, R., Coudel, E., \& Steward, A. M. (2019). Forbidden fire: Does criminalising fire hinder conservation efforts in swidden landscapes of the Brazilian Amazon? The Geographical Journal, 185, 23-37. https://doi.org/10.1111/geoj.12255.

Chidumayo, E. N. (2013). Effects of seed burial and fire on seedling and sapling recruitment, survival and growth of African savanna woody plant species. Plant Ecology, 214, 103-114. https://doi.org/10.1007/s11258-012-0149-7.

Christianini, A. V., \& Galetti, M. (2007). Spatial variation in post-dispersal seed removal in an Atlantic forest: Effects of habitat, location and guilds of seed predators. Acta Oecologica-International Journal of Ecology, 32, 328-336. https://doi.org/10.1016/ j.actao.2007.06.004.

Cole, R. J. (2009). Postdispersal seed fate of tropical montane trees in an agricultural landscape, southern Costa Rica. Biotropica, 41, 319-327. https://doi.org/10.1111/j.1744-7429.2009.00490.x.

Costa, A. N., Vasconcelos, H. L., \& Bruna, E. M. (2017). Biotic drivers of seedling establishment in Neotropical savannas: Selective granivory and seedling herbivory by leaf-cutter ants as an ecological filter. Journal of Ecology, 105, 132-141. https:// doi.org/10.1111/1365-2745.12656.

Cressie, N. A. C. (1993). Statistics for spatial data. Wiley. 
Curran, L. M., \& Webb, C. O. (2000). Experimental tests of the spatiotemporal scale of seed predation in mast-fruiting Dipterocarpaceae. Ecological Monographs, 70, 129-148. https://doi.org/10.1890/0012-9615(2000)070[0129:ETOTSS]2.0. $\mathrm{CO} ; 2$.

Davies, A. B., Eggleton, P., van Rensburg, B. J., \& Parr, C. L. (2012). The pyrodiversity-biodiversity hypothesis: A test with savanna termite assemblages. Journal of Applied Ecology, 49, 422-430. https://doi.org/10.1111/j.1365-2664.2012.02107.x.

Eloy, L., Bilbao, B. A., Mistry, J., \& Schmidt, I. B. (2019). From fire suppression to fire management: Advances and resistances to changes in fire policy in the savannas of Brazil and Venezuela. The Geographical Journal, 185, 10-22. https://doi. org/10.1111/geoj.12245.

Ferreira, A. S., Peres, C. A., Dodonov, P., \& Cassano, C. R. (2020). Multi-scale mammal responses to agroforestry landscapes in the Brazilian Atlantic Forest: The conservation value of forest and traditional shade plantations. Agroforestry Systems, $\mathbf{9 4}$ 2331-2341. https://doi.org/10.1007/s10457-020-00553-y.

Ferreira, A. V., Bruna, E. M., \& Vasconcelos, H. L. (2011). Seed predators limit plant recruitment in Neotropical savannas. Oikos, 120, 1013-1022. https://doi.org/10.1111/j.1600-0706.2010.19052.x.

Hulme, P. E. (1998). Post-dispersal seed predation: Consequences for plant demography and evolution. Perspectives in Plant Ecology, Evolution and Systematics, 1, 32-46.

Kaspari, M. (1993). Removal of seeds from neotropical frugivore droppings-Ant responses to seed number. Oecologia, 95, $81-88$.

Lambers, H., de Britto Costa, P., Oliveira, R. S., \& Silveira, F. A. O. (2020). Towards more sustainable cropping systems: Lessons from native Cerrado species. Theoretical and Experimental Plant Physiology, 32, 175-194. https://doi.org/10.1007/ s40626-020-00180-z.

Lapola, D. M., Martinelli, L. A., Peres, C. A., Ometto, J. P., Ferreira, M. E., Nobre, C. A., Aguiar, A. P. D., Bustamante, M. M., Cardoso, M. F., Costa, M. H., Joly, C. A., Leite, C. C., Moutinho, P., Sampaio, G., Strassburg, B. B. N., \& Vieira, I. C. G. (2014). Pervasive transition of the Brazilian land-use system. Nature Climate Change, 4, 27-35. https://doi. org/10.1038/nclimate2056.

Legendre, P. (1993). Spatial autocorrelation: Trouble or new paradigm? Ecology, 74, 1659-1673. https://doi.org/10.2307/ 1939924.

Logan, J. W. M., Cowie, R. H., \& Wood, T. G. (1990). Termite (Isoptera) control in agriculture and forestry by non-chemical methods: A review. Bulletin of Entomological Research, 80, 309-330. https://doi.org/10.1017/S0007485300050513.

Maravalhas, J., \& Vasconcelos, H. L. (2014). Revisiting the pyrodiversity-biodiversity hypothesis: Long-term fire regimes and the structure of ant communities in a Neotropical savanna hotspot. Journal of Applied Ecology, 51, 1661-1668. https://doi. org/10.1111/1365-2664.12338.

Miccolis, A., Peneireiro, F. M., Vieira, D. L. M., Marques, H. R., \& Hoffmann, M. R. M. (2017). Restoration through agroforestry: Options for reconciling livelihoods with conservation in the Cerrado and Caatinga biomes in Brazil. Experimental Agriculture, 55, 208-225. https://doi.org/10.1017/S0014479717000138.

Moura, L. C., Scariot, A. O., Schmidt, I. B., Beatty, R., \& Russell-Smith, J. (2019). The legacy of colonial fire management policies on traditional livelihoods and ecological sustainability in savannas: Impacts, consequences, new directions. Journal of Environmental Management, 232, 600-606. https://doi.org/10.1016/j.jenvman.2018.11.057.

Norris, D., \& Michalski, F. (2010). Implications of faecal removal by dung beetles for scat survey in a fragmented landscape of the Braziliam Amazon. Oryx, 44, 455-458. https://doi.org/10.1017/S0030605309990809.

Nwosu, L. C., \& Akor, J. B. (2018). Termite diversity, agronomic implications and control strategies in a farming district, Naka, Benue State, Nigeria. Nigerian Journal of Agriculture, Food and Environment, 14, 20-24.

Oliveira, P. S., \& Freitas, A. V. L. (2004). Ant-plant-herbivore interactions in the neotropical cerrado savanna. Naturwissenschaften, 91, 557-570. https://doi.org/10.1007/s00114-004-0585-x.

R Development Core Team. (2019). R: A language and environment for statistical computing (Version 3.6.1). R Foundation for Statistical Computing. http://www.R-project.org/.

Ribeiro, P. J., Jr., \& Diggle, P. J. (2001). geoR: A package for geostatistical analysis. R-News, 1, 15-18.

Santos, P. Z. F., Crouzeilles, R., \& Sansevero, J. B. B. (2019). Can agroforestry systems enhance biodiversity and ecosystem service provision in agricultural landscapes? A meta-analysis for the Brazilian Atlantic Forest. Forest Ecology and Management, 433, 140-145. https://doi.org/10.1016/j.foreco.2018.10.064.

Souza-Silva, H., Machado, L. F., Silva, J. O., \& Espirito-Santo, M. M. (2015). Consequences of habitat disturbance on seed fate of a Brazilian tropical dry forest tree Cavanillesia arborea (Malvaceae). Austral Ecology, 40, 726-732. https://doi.org/10.1111/ aec.12241.

Tasker, E. M., Denham, A. J., Taylor, J. E., \& Strevens, T. C. (2011). Post-fire seed predation: Does distance to unburnt vegetation matter? Austral Ecology, 36, 755-766. https://doi.org/10.1111/j.1442-9993.2010.02214.x.

Vieira, D. L. M., Holl, K. D., \& Peneireiro, F. M. (2009). Agro-Successional Restoration as a Strategy to Facilitate Tropical Forest Recovery. Restoration Ecology, 17, 451-459. https://doi.org/10.1111/j.1526-100X.2009.00570.x. 
Wickham, H., Averick, M., Bryan, J., Chang, W., McGowan, L. D. A., François, R., Grolemund, G., Hayes, A., Henry, L., Hester, J., Kuhn, M., Pedersen, T. L., Miller, E., Bache, S. M., Müller, K., Ooms, J., Robinson, D., Seidel, D. P., Spinu, V., Yutani, H. (2019). Welcome to the tidyverse. Journal of Open Source Software, 4, 1686. https://doi.org/10.21105/joss.01686. Yamada, M., \& Gholz, H. L. (2002). An evaluation of agroforestry systems as a rural development option for the Brazilian Amazon. Agroforestry Systems, 55, 81-87. https://doi.org/10.1023/A:1020523107243.

Cite this article: Rodriguez Chuma VJUR, Norris D, da Silva TP, da Silva JA, Cavalcante KS, Sidônio IAP, de Souza AF, Valentim DSS, Mochiutti S, Michalski F (2021). Preparation burning may not improve short-term seed survival in an Amazonian savanna Experimental Results, 2, e12, 1-11. https://doi.org/10.1017/exp.2021.2 


\title{
Peer Reviews
}

\section{Reviewing editor: Dr. Michael Nevels}

University of St Andrews, Biomolecular Sciences Building, Fife, United Kingdom of Great Britain and Northern Ireland, KY16 9ST

This article has been accepted because it is deemed to be scientifically sound, has the correct controls, has appropriate methodology and is statistically valid, and has been sent for additional statistical evaluation and met required revisions.

doi:10.1017/exp.2021.2.pr1

\section{Review 1: Preparation burning does not improve short-term seed survival in an Amazon savanna}

\author{
Reviewer: Dr. Alan N. Costa
}

Universidade Federal de Uberlandia, Instituto de Biologia, Uberlandia, Minas Gerais, Brazil, 38408-100

Date of review: 28 January 2021

\begin{abstract}
(C) The Author(s), 2021. Published by Cambridge University Press. This is an Open Access article, distributed under the terms of the Creative Commons Attribution licence (http://creativecommons.org/licenses/by/4.0), which permits unrestricted re-use, distribution and reproduction, provided the original article is properly cited.
\end{abstract}

Conflict of interest statement. Revierwer declares none

Comments to the Author: The topic of the research, the effect of preparation burning on short-term seed survival in Amazonian savannas, is very interesting, with an important practical aspect. In general, the manuscript was well written, easy to follow and I found the statistical analyses to be appropriate. However, I have some comments and small suggestions for the authors.

Comments for the authors

In the title, the authors state that preparing burning doesn't improve seed survival. This looks true when focusing on the great increase of infestation rate observed for palm seeds in the burned savanna. In contrast, the seed remotion rate for popcorn was the smallest in the burned savanna, reaching also the highest rate for intact seeds of popcorn. For me, this might indicate a speciesspecific effect, with a decrease of attacks on less attractive seeds (i.e., they without pulp, arils, or other attractive substances, as kernels), while it'd be observed an increase of attacks on fruits and seeds with pulp or arils, as fruits of Açaí). So, it'd be good for some species and worse for others. Could this hypothesis be considered?

This brings me to another question. Could the infestation by invertebrates (in this case, mainly termites, line 140) reduce the short-term survival of palm seeds? The cited references confirm the importance of invertebrates, however, mainly ants, on seed bank diversity, with potential consequences for the structure and composition of savanna vegetation. I confess that I have doubts whether termites would consume the seeds, behind to immediately explore only their fruit pulp. In the first situation, a negative impact on seed survival would be expected, but maybe not in the second case. Were the infested seeds consumed, at least in part, by insects? I think this important and suggest to the authors include some references that confirm termites, and consequently the referred insect infestation, as a potential seed predator and their presence with potential impact on short-term survival of seeds. 
In the Abstract, the authors omitted the third habitat (riparian forest). However, the major difference in seed remotion occurred just between forest and savanna habitats for both palm and popcorn, which was likely the great responsible for the significant difference observed among habitats. So, I think that is correct to include the forest habitat in the result presentation of the abstract, with the appropriate adjustments.

\section{Minor reviews}

Line 33: Without cite the riparian forest in the abstract as a study habitat, it was strange to attest that "savanna" had the highest overall seed infestation rate. Higher than who?

Line 49: Remove the name initials in Ferreira et al, 2011 and 2020 across the text.

Line 70: Clarify in methods was considered insect infestation. Was the presence of insects on and/or in fruits and seeds?

Line 83: Throughout the text, the authors alternated the use of two terms: "riparian forest" or "riparian savanna forest". What would be a riparian savanna forest? Isn't possible to include a short description of vegetation found in study habitats. It' $\mathrm{d}$ be useful for readers unfamiliar with the Brazilian ecosystems.

Line 126: Replace 'number' with 'rate'.

Line 136: Include the word 'may' in 'how both insects and fire may influence the structure... I think this important to appear less emphatic. The same could be done in other parts of the text, as in the title: “... may not improve short-term ...", but it's just a suggestion.

\section{Score Card}

Presentation

Is the article written in clear and proper English? (30\%)

Is the data presented in the most useful manner? (40\%)

Does the paper cite relevant and related articles appropriately? (30\%)

\section{Context}

Does the title suitably represent the article? (25\%)

Does the abstract correctly embody the content of the article? (25\%)

Does the introduction give appropriate context? (25\%)

Is the objective of the experiment clearly defined? (25\%)

Analysis

Are the limitations of the experiment as well as the contributions of the experiment clearly outlined? $(20 \%)$ 


\section{Review 2: Preparation burning does not improve short-term seed survival in an Amazon savanna}

Reviewer: Dr. L Davenport (1D

Date of review: 01 February 2021

(C) The Author(s), 2021. Published by Cambridge University Press. This is an Open Access article, distributed under the terms of the Creative Commons Attribution licence (http://creativecommons.org/licenses/by/4.0), which permits unrestricted re-use, distribution and reproduction, provided the original article is properly cited.

Conflict of interest statement. Reviewer declares none

Comments to the Author: I believe the work is nearly finished. A few requests:

Abstract. The final sentence is exceptionally big leap of faith from a small statement, though later on, you do make caveats appropriately. I would tone down, however.

line 48 (and throughout) a better descriptor is "Amazonian" rather than "Amazon." Avoid using nouns as adjectives where able.

line 59: the "it" refers back to "fire regimes" so should be plural, or change to "fire"

line 108 - which R packages were used?

\section{Score Card}

Presentation

5.0

Is the article written in clear and proper English? (30\%)

Is the data presented in the most useful manner? (40\%)

Does the paper cite relevant and related articles appropriately? (30\%)

\section{Context}

Does the abstract correctly embody the content of the article? (25\%)

Does the introduction give appropriate context? (25\%)

Is the objective of the experiment clearly defined? (25\%)

Analysis

Are the limitations of the experiment as well as the contributions of the

experiment clearly outlined? (20\%) 